\title{
Aerosol optical properties derived from POLDER-3/PARASOL (2005-2013) over the western Mediterranean Sea - Part 1: Quality assessment with AERONET and in situ airborne observations
}

\author{
P. Formenti et al. \\ Correspondence to: Paola Formenti (paola.formenti@lisa.u-pec.fr)
}

The copyright of individual parts of the supplement might differ from the CC BY 4.0 License. 
5 Table S1. Modal diameter $\left(D_{0}\right)$, geometric standard deviation $\left(\sigma_{0}\right)$ and effective diameter $\left(D_{\text {eff }}\right)$ of the 6 log-normal distribution as well as real part of the refractive index $\left(m_{r}\right)$ of the aerosol models over ocean 7 of the POLDER-3 Look-Up Table (LUT). The imaginary part of the refractive index $\left(m_{i}\right)$ is assumed as 8 zero.

\begin{tabular}{|c|c|c|c|}
\hline Parameters & Fine mode & Spherical coarse mode & $\begin{array}{c}\text { Non spherical coarse } \\
\text { mode }\end{array}$ \\
\hline$D_{0}(\mu \mathrm{m})$ & $0.08,0.16,0.20,0.26$ & 1.56 & $0.90,1.50$ \\
\hline$\sigma_{0}$ & 0.46 & 0.69 & 0.69 \\
\hline$D_{\text {eff }}(\mu \mathrm{m})$ & $0.136,0.272,0.34,0.442$ & 5.10 & $2.96,4.92$ \\
\hline$m_{r}$ & $1.35,1.45,1.60$ & $1.33,1.35,1.37$ & 1.53 \\
\hline
\end{tabular}

9 
Figure S1. Iterative data inversion procedure to retrieve from airborne observations the aerosol optical depth (AOD, $A O D_{F}$ and $A_{C D}$ ) and Angstrom exponent (AE) as measured by POLDER-3. Green boxes indicate the input values from airborne measurements (size distribution, scattering and extinction coefficients) and the initial values of the complex refractive indices estimated from published literature. The iterative steps of the procedure are indicated in the blue boxes. The results of optical calculations (corrected size distribution, scattering and extinction coefficients) are in the orange boxes.

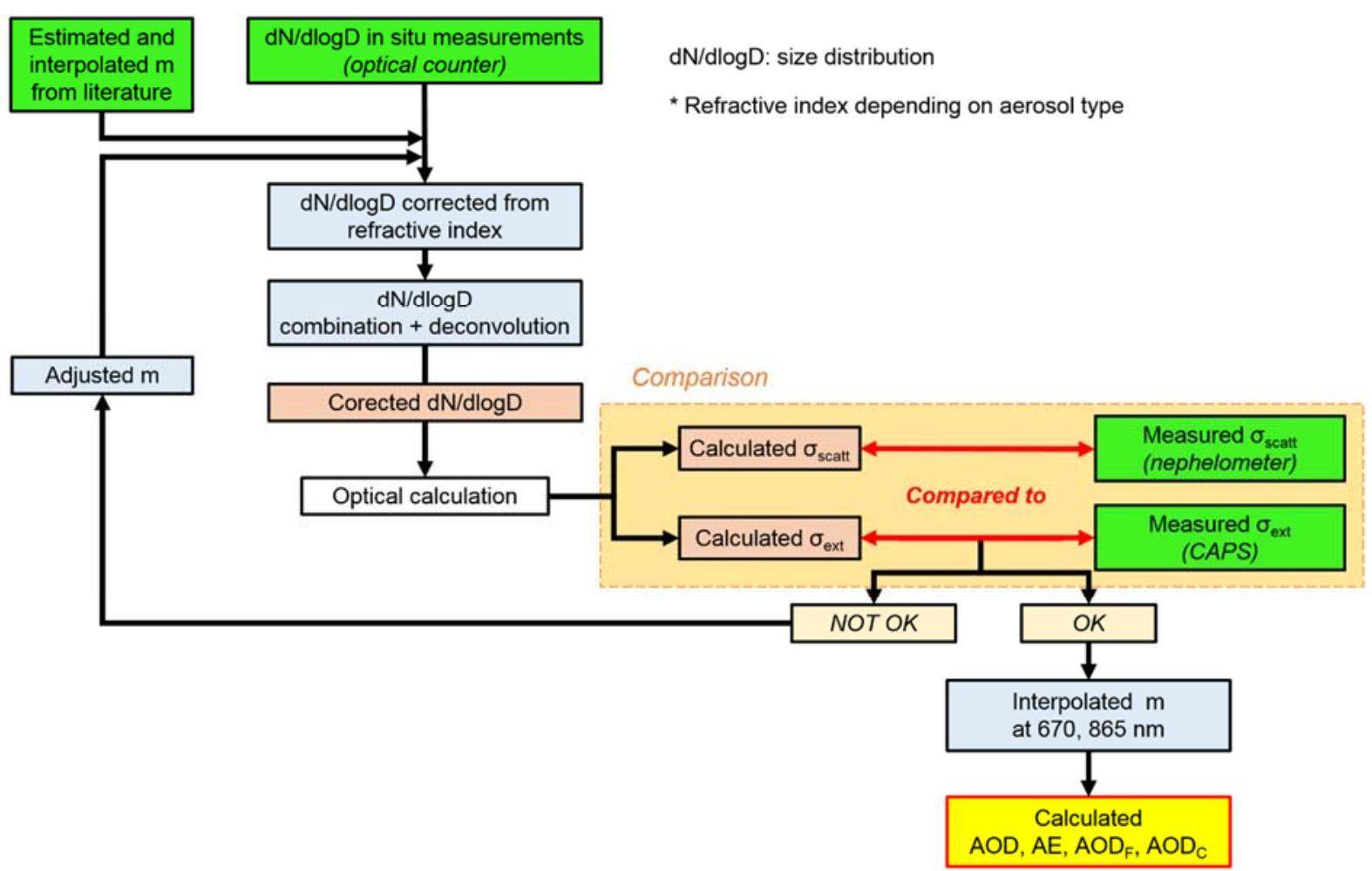


22 Figure S2. Ratio of the coarse to the total AOD (AOD $/ A O D)$ by AERONET as a function of 23 the cut-off diameter $\left(D_{\text {cut-off }}\right)$ between the fine and coarse aerosol particle modes.

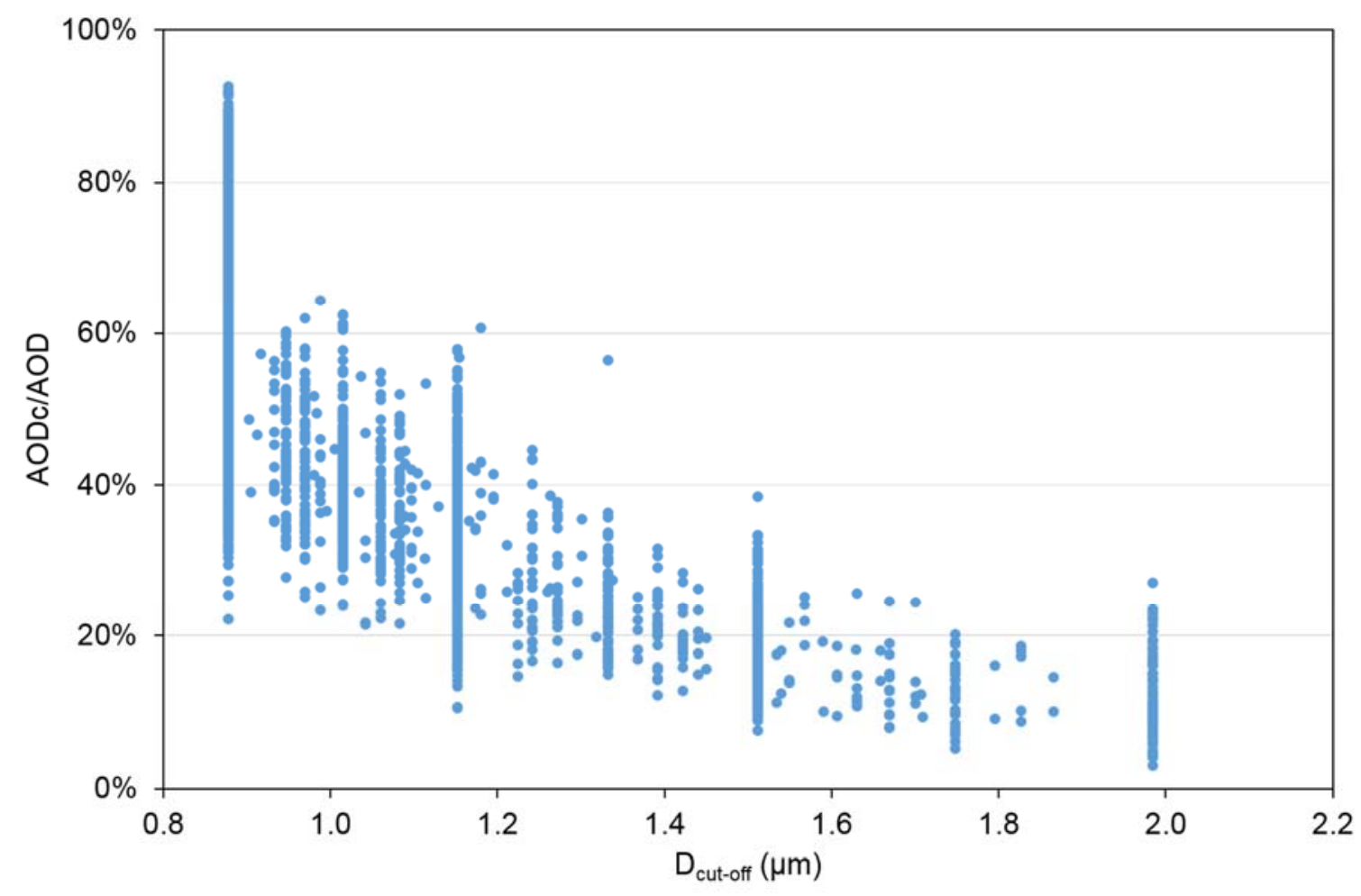




\section{Supplementary A. Assessment of the size distribution}

27 Here we provide details of the procedure to estimate the aerosol particle size distribution from the measurements of the PCASP, UHSAS and Grimm optical counters operated on board the ATR42 during TRAQA and ADRIMED. This also requires to assess the particles complex refractive index.

\section{S.1. Correction for complex refractive index}

32

The operating principle of the particle optical counters is based on the angular dependence of the light scattering intensity to the particle size through optical Mie theory (Mie, 1908; Wendisch and Brenguier, 2013). The optical particle counters provide the number size distribution at an optical equivalent diameter $\left(D_{E O}\right)$ corresponding to the measured intensity of the scattered radiation at the value of the complex refractive index $m$ used for calibration. This is generally done with latex spheres (or equivalent standard material) for which $m$ is equal to $1.59-$ i0 at $638 \mathrm{~nm}$. Henceforth, to represent the actual aerosol, the value of $D_{E O}$ needs to be converted into a particle equivalent geometrical diameter $\left(D_{E G}\right)$, corresponding to the real value of the complex refractive index. This correction depends on aerosol composition and the geometrical and spectral characteristics of the particle counter (Reid et al., 2003; Denjean et al, 2016).

The equivalence between $D_{E O}$ and $D_{E G}$ was established by calculation using the Mie theory for homogeneous spherical particles (Bohren and Huffman, 1998). Examples of this equivalence for a range of $m$ values is shown in Figure $S 3$ for the particle optical counters used in this study (UHSAS, PCASP and Grimm). 

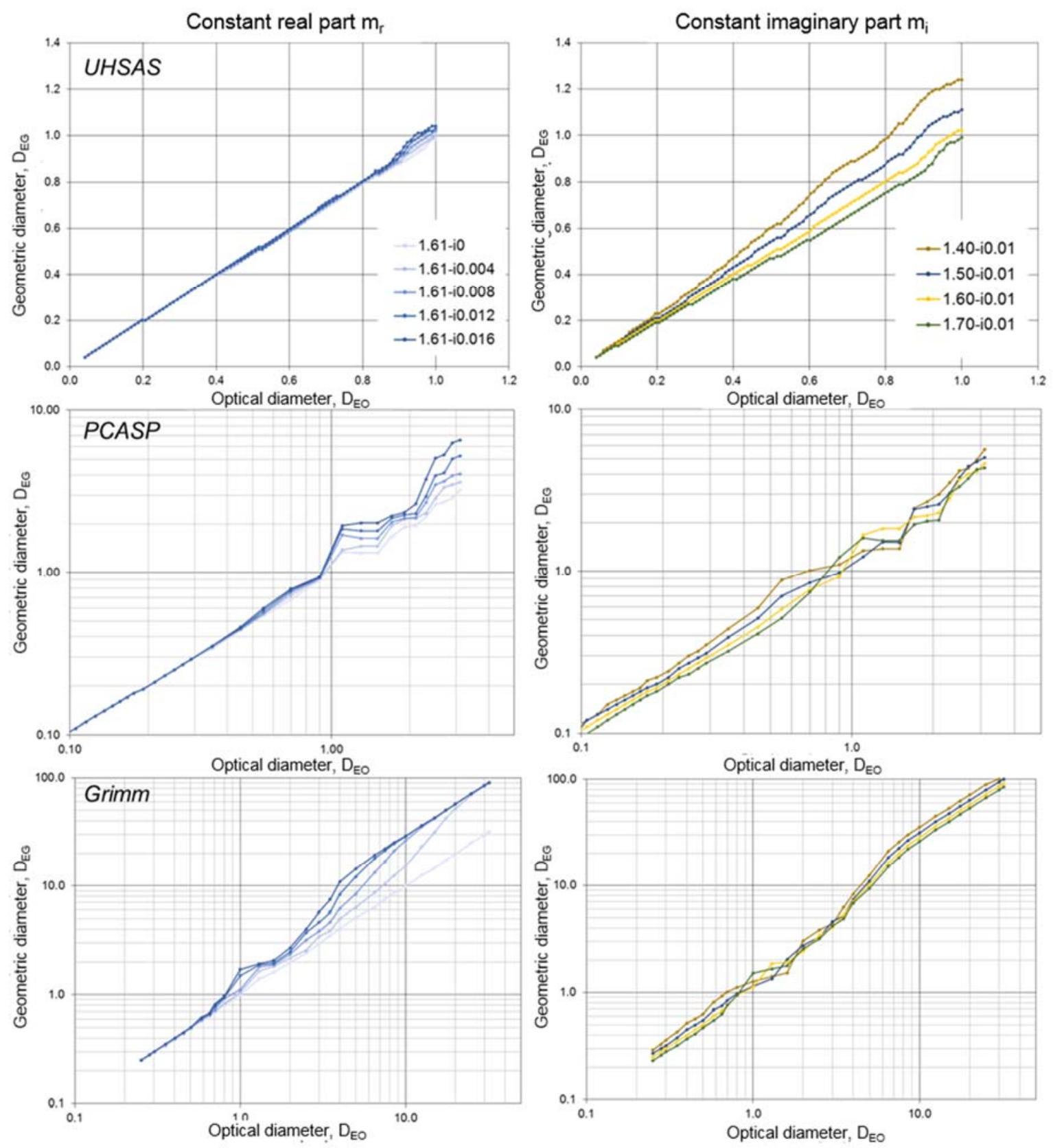

Figure S3. Scatterplot of the geometric-equivalent diameter $\left(D_{E G}\right)$ with respect to the optical-equivalent diameter $\left(D_{E O}\right)$ for various refractive indices with real part fixed at 1.61 (left) and imaginary part fixed at 0.01 (right), for UHSAS (top), PCASP (middle), and Grimm (bottom).

The relation between $D_{E O}$ and $D_{E G}$ is not linear with size. The real and imaginary parts of the refractive index modify significantly the particle diameter, notably above $0.6 \mu \mathrm{m}$. The imaginary part of the refractive index has a greater influence at diameters larger than $1 \mu \mathrm{m}$, whereas the real part affects more the submicron aerosols. Figure S3 also shows the equivalence between $D_{E O}$ and $D_{E G}$ is not unique, especially for $D_{E O}$ around $1 \mu \mathrm{m}$. 


\section{S.2. Combination of optical counter measurements}

58

60

61

62

63

64

65

66

67

68

69

70

71

72

73

74

75

76

77

\section{(1)}

The combination of the size spectra measured by the PCASP, UHSAS, and Grimm was performed by examining their overlap over their common measurement size ranges. The combination was performed as follows. First, the measured size distributions were visually inspected to establish whether, at the calibration refractive index $\left(m_{\text {latex }}=1.59-0 \mathrm{i}\right)$, the observations by the counters coincided on their common size range. This analysis was repeated after applying the geometric equivalence correction according to the refractive index (that is, on the size distributions expressed as a function of $D_{E G}$ ). When the difference between the particle number concentration measured by the two counters (at pairs) was lower than the sum of the absolute counting errors ( $\sqrt{ } \mathrm{d} N$ according to the Poisson statistics), the agreement was considered as satisfactory. A boundary diameter $\left(D_{\text {cover }}\right)$ was then defined in the overlap zone to generate a new combined size distribution from the PCASP or UHSAS in the particle diameter range $D^{\prime}{ }_{E G} \leq D_{\text {COVER }}$ and the Grimm counter in the range $D^{\prime \prime}{ }_{E G} \geq D_{\text {COVER }}$ (with $D{ }_{E G}$ up to the AVIRAD inlet cut-off diameter), so that

$$
\frac{d N_{t o t}\left(D_{E G}\right)}{\operatorname{dlog} D_{E G}}=\frac{d N_{P C A S P}\left(D_{E G}^{\prime}\right)}{\operatorname{dlog} D_{E G}^{\prime}}+\frac{d N_{G} \operatorname{rimm}\left(D_{E G}^{\prime \prime}\right)}{\operatorname{dlog} D_{E G}^{\prime \prime}}
$$

$$
\frac{d N_{t o t}\left(D_{E G}\right)}{\operatorname{dlog} D_{E G}}=\frac{d N_{U H S A S}\left(D_{E G}^{\prime}\right)}{\operatorname{dlog} D_{E G}^{\prime}}+\frac{d N_{G r i m m}\left(D_{E G}^{\prime \prime}\right)}{\operatorname{dlog} D_{E g}^{\prime \prime}}
$$

Figure S4 shows a schematic representation of the combination between both size distributions. 


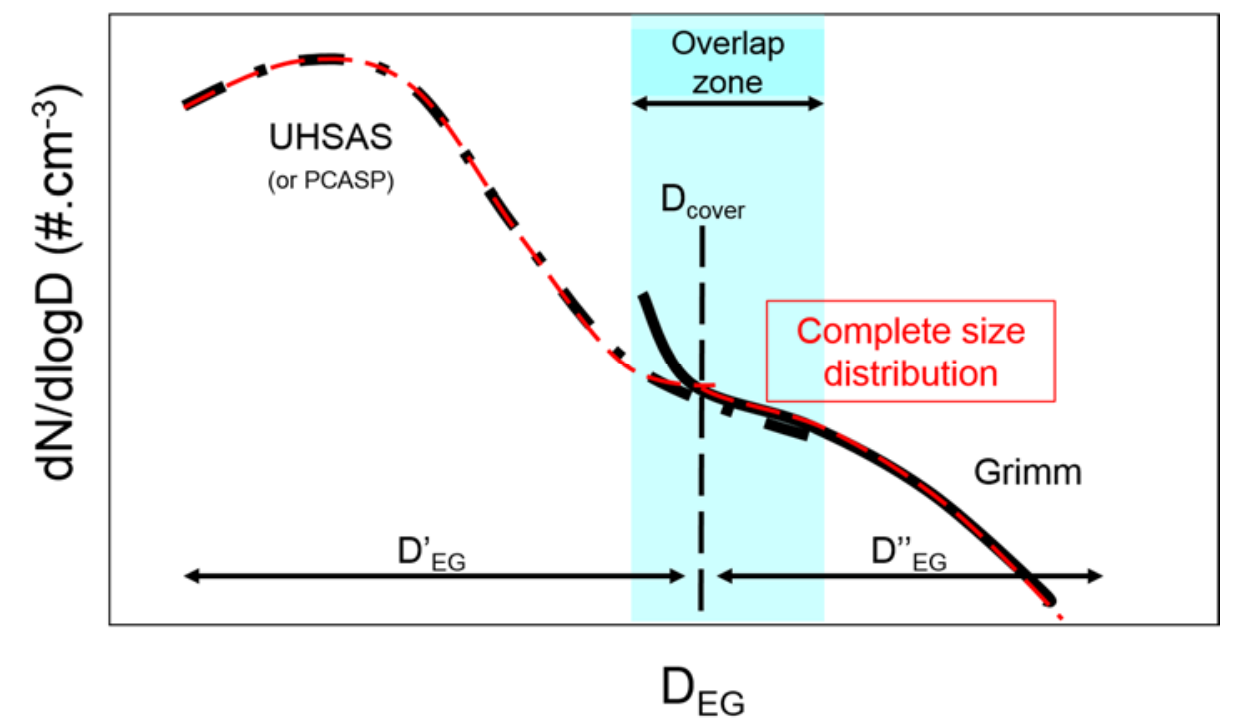

$$
N_{E O}=\int_{D_{E O, \min }}^{D_{E O, \max }} \frac{d N_{E O}\left(D_{E O}\right)}{d \log D_{E O}} d \log D_{E O}
$$
and Grimm around $D_{\text {cover }}$. The overlap zone is indicated in blue. The black curves represent the distributions measured by the two counters in pairs, corrected by the refractive index (e.g., expressed as $D_{E G}$ ). The red curves represent the combined size distributions of the two optical counters over the combination of the domain of $D_{E G}$ ' (for UHSAS or PCASP) and $D_{E G}$ " for the Grimm. In each diameter range below and over $D_{C O V E R}$, $\operatorname{dlog} D_{E G}$ values and counting errors remain those of the respective counter.

The overlapping zone changes whether we work with PCASP (TRAQA campaign) or UHSAS (ADRIMED campaign). $D_{\text {cover }}$ ranged between 0.23 and $0.7 \mu \mathrm{m}$ for the TRAQA campaign when the PCASP and the Grimm were operated, and between 0.23 and $0.9 \mu \mathrm{m}$ during ADRIMED when the UHSAS and the Grimm were operated.

To make sure that the total number of particles was conserved after the recombination and the modification of the size classes by the refractive index, we applied the conservation equation of the total number of particles

$$
N_{E G}=N_{E O}
$$

Figure S4. Schematics of the combination of the number size distributions between UHSAS (or PCASP) 


$$
N_{E G}=\int_{D_{E G, \min }}^{D_{E G} \max } \frac{d N_{E G}\left(D_{E G}\right)}{\operatorname{dlog} D_{E G}} d \log D_{E G}
$$

where $N_{E O}$ is the total number of particles corresponding to the measurement (for the refractive index $\left.m_{\text {latex }}\right)$ and $N_{E G}$ is the total number of particles after correction of the refractive index.

103 Finally, the extended size distributions $\frac{d N_{E G}\left(D_{E G}\right)}{d \log D_{E G}}$ obtained by the recombination of the optical particle counters were fitted by a multi modal normalized log-normal distributions as

$$
\frac{1}{N_{E G}} \frac{d N_{E G}\left(D_{E G}\right)}{\operatorname{dlog} D_{E G}}=\sum_{i} \frac{n_{i}}{\sigma_{i} \sqrt{2 \pi}} \exp \left(-\frac{\left(\log D-\log D_{0, i}\right)^{2}}{2 \sigma_{i}^{2}}\right)
$$

where $n_{i}$ is the total number of particles, $\sigma_{i}$ the geometric standard deviation and $D_{0, i}$ the modal (geometric mean) diameter of the mode $i$.

110 The log-normal fit of the reconstructed size distribution was done with the MPFIT routine 111 available under IDL (Markwardt, 2009; http://purl.com/net/mpfit). The calculation routine 112 considers the result as correct if the difference $\varepsilon_{F I T}$ between the sum of the squares of the input 113 size distribution and its deconvolution is less than $10^{-10}$ after 100 iterations. To limit error due 114 to an over- or underestimation of the total number of particle $N_{E G}$, not constrained in this 115 routine, the calculation was repeated several times, on normalized size distributions, by modifying the initial parameters until the calculated size distribution is within the limits of the

117 counting uncertainties of the experimental size distributions. Examples of deconvolutions are 118 shown in Figure S5. 

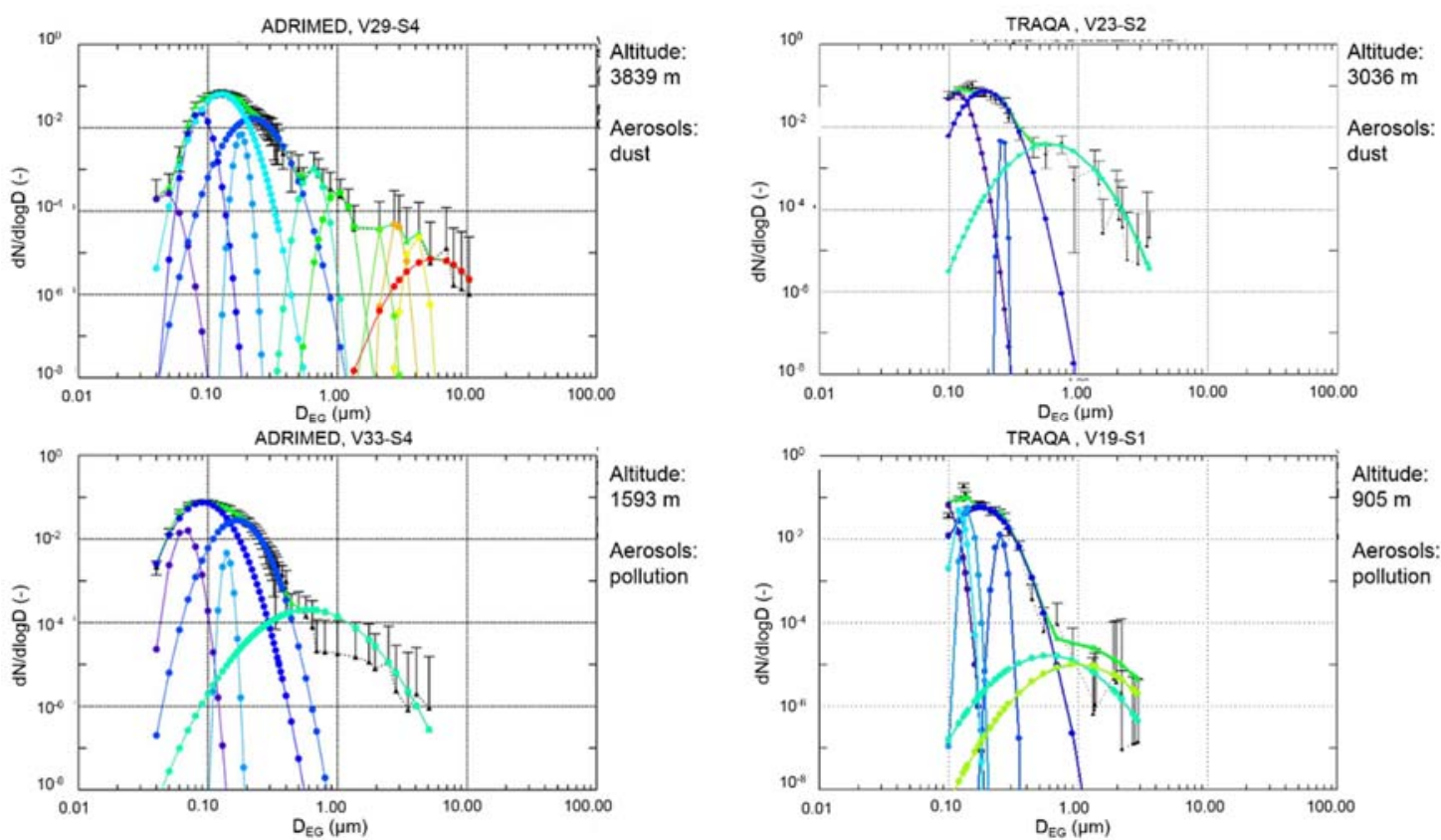

- Size distribution

Déconvolution

- Mode 1

Mode 2

Mode 3

Mode 4

Mode 5

Mode 6

Mode 7

Mode 8

Mode 9

Mode 10

Mode 10

Mode 11

Mode 12

Mode 14

- Mode 15

Figure S5. Examples of reconstructed normalized number size distributions and their decomposition in log-normal modes for case studies of desert dust (upper panels) and pollution aerosols (lower panels) during ADRIMED and TRAQA. The deconvolution was performed with the IDL MPFIT routine for up to

Up to 11 modes were needed to fit the size distributions, of which up to 6 modes for $D_{E G}<1$ $\mu \mathrm{m}$. These do not necessarily have a physical meaning but are regarded as a way of reproducing the volume distribution at the highest possible size resolution.

\section{S.3. Assessment of the complex refractive index}

The complex refractive index necessary to estimate $D_{E G}$, and therefore correct the measured size distributions according to the optical equivalent diameter $D_{E O}$, are based on published values in the literature, some of them especially for our region of study (Ackermann, 1998; Petzold et al., 2009; Ryder et al., 2013; Di Biagio et al., 2015; Denjean et al., 2016; Sicard et al., 2016). The different values are presented in Table S2. 


\begin{tabular}{|c|c|c|c|c|}
\hline Aerosol & Campaign & $\begin{array}{c}\text { Wavelength } \\
(\mathrm{nm})\end{array}$ & Refractive index & References \\
\hline $\begin{array}{c}\text { Pollution } \\
\text { (fine mode) }\end{array}$ & TRAQA, SAFMED & 632.8 & $(1.50-1.72)-i 0.01$ & Di Biagio et al., 2015 \\
\hline \multirow{3}{*}{$\begin{array}{l}\text { Pollution } \\
\text { (soot) }\end{array}$} & \multirow{3}{*}{---} & 355 & $1.75-i 4.6410^{-1}$ & \multirow{3}{*}{ Ackermann, 1998} \\
\hline & & 532 & $1.75-i 4.4610^{-1}$ & \\
\hline & & 1064 & $1.76-i 1.4310^{-1}$ & \\
\hline \multirow{3}{*}{ Marine } & \multirow{3}{*}{---} & 355 & $1.51-i 3.2210^{-8}$ & \multirow{3}{*}{ Ackermann, 1998} \\
\hline & & 532 & $1.50-i 1.1210^{-8}$ & \\
\hline & & 1064 & $1.47-i 1.9210^{-4}$ & \\
\hline \multirow{8}{*}{ Desert dust } & \multirow{3}{*}{---} & 355 & $1.53-i 1.6610^{-2}$ & \multirow{3}{*}{ Ackermann, 1998} \\
\hline & & 532 & $1.53-i 6.3310^{-3}$ & \\
\hline & & 1064 & $1.53-i 4.3010^{-3}$ & \\
\hline & ADRIMED & 530 & $(1.51-1.57)-i(1.0-4.6) 10^{-3}$ & Denjean et al., 2016 \\
\hline & \multirow{3}{*}{ SAMUM } & 450 & $(1.55-1.57)-i(3.1-5.2) 10^{-3}$ & \multirow{3}{*}{ Petzold et al., 2009} \\
\hline & & 550 & $(1.55-1.56)-i(1.6-4.2) 10^{-3}$ & \\
\hline & & 700 & $(1.55-1.56)-i(0.3-2.5) 10^{-3}$ & \\
\hline & FENNEC & 550 & $1.53-i(1.0-3.0) 10^{-3}$ & Ryder et al., 2013 \\
\hline $\begin{array}{c}\text { Mixed } \\
\text { aerosols }\end{array}$ & AERONET & 440 & $(1.42-1.48)-i(2.8-4.7) 10^{-3}$ & Sicard et al., 2016 \\
\hline
\end{tabular}

Table S2. Compilation of published values of refractive index and their wavelengths, for different aerosol type with some of them especially for our region of study (Mediterranean Sea).

In the absence of complementary information on the variability of the chemical composition with size, the refractive index was considered as independent on particle size. The refractive index for mixed aerosols $\left(A E_{\text {scat }}\right.$ between 0.5 and 1.0) was calculated as volume-weighted averages of pollution aerosols and desert dust as

$$
\mathrm{m}=\sum_{\mathrm{i}} \mathrm{f}_{\mathrm{i}} \times \mathrm{m}_{\mathrm{i}}
$$

where $f_{i}$ et $m_{i}$ are the volume fractions and the complex refractive index of two types of aerosols $i$, respectively. We assumed arbitrarily that $f_{i}=0.8$ for desert dust and $f_{i}=0.2$ for pollution aerosols for $A E_{\text {scat }} \leq 0.75$, and $f_{i}=0.2$ for desert dust and $f_{i}=0.8$ for pollution aerosols for $A E_{\text {scat }}$ $>0.75$. The extrapolation to our working wavelengths $(450,532,550,700$ and $865 \mathrm{~nm})$ was done by assuming the spectral dependences obtained by Ackermann (1998) between 355 and $532 \mathrm{~nm}$ and between 532 and and $1064 \mathrm{~nm}$. The spectral dependence was applied to the refractive index for desert dust and mixed aerosols obtained by Di Biagio et al. (2016) and Denjean et al. (2016) for case studies during TRAQA and ADRIMED. 

scattering coefficient

158 The validation of the number size distributions reconstructed from airborne measurements, 159 henceforth their ability in yielding the column-integrated but size-segregated extinction, was 160 assessed by calculating, on 30-second averages, the extinction coefficient $\sigma_{\text {ext }}$ at $532 \mathrm{~nm}$ and 161 the scattering coefficient $\sigma_{\text {scat }}$ at 450,550 and $700 \mathrm{~nm}$, and by comparing them to $\sigma_{\text {ext }}$ measured 162 by the CAPS-PMex (only operated during ADRIMED) and to $\sigma_{\text {scat }}$ measured by the 163 nephelometer, respectively. The comparisons were evaluated by examining the correlation 164 coefficient $\mathrm{R}$, the root-mean square error (RMS) and the bias (B) of their linear regression. The 165 complex refractive index at each wavelength was varied until the best agreement between 166 calculated and measured $\sigma_{s c a t}$ and $\sigma_{\text {ext }}$ was achieved within the estimated error bars. The 167 retrieved refractive index matching measurements and calculations are summarized in Table 168 S3. 


\begin{tabular}{|c|c|c|c|c|c|c|c|c|c|}
\hline \multirow{2}{*}{ Aerosol type } & \multicolumn{9}{|c|}{ Complex refractive index $m$} \\
\hline & $450 \mathrm{~nm}$ & $532 \mathrm{~nm}$ & $550 \mathrm{~nm}$ & $632.5 \mathrm{~nm}$ & $655 \mathrm{~nm}$ & $670 \mathrm{~nm}$ & $700 \mathrm{~nm}$ & $865 \mathrm{~nm}$ & $1054 \mathrm{~nm}$ \\
\hline $\begin{array}{c}\text { Clear layer } I \\
\text { maritime }\end{array}$ & \multicolumn{9}{|c|}{$(1.40-1.50)-\mathrm{i}(0-0.002)$} \\
\hline Desert dust & $\begin{array}{c}(1.50-1.57)- \\
\mathrm{i}(0.004-0.007)\end{array}$ & \multicolumn{6}{|c|}{$(1.50-1.57)-\mathrm{i}(0.002-0.004)$} & $\begin{array}{l}(1.50-1.57)- \\
\mathrm{i}(0.0020 .003)\end{array}$ & $\begin{array}{c}(1.50-1.57)- \\
i(0.001-0.003)\end{array}$ \\
\hline Pollution & $\begin{array}{l}(1.41-1.77)- \\
\mathrm{i}(0.002-0.022)\end{array}$ & $\begin{array}{c}(1.41-1.77)- \\
\mathrm{i}(0.002-0.018)\end{array}$ & $\begin{array}{c}(1.41-1.77)- \\
\mathrm{i}(0.002-0.017)\end{array}$ & $\begin{array}{c}(1.41-1.77)- \\
\mathrm{i}(0.002-0.015)\end{array}$ & $\begin{array}{r}(1.41-1.77)-- \\
\mathrm{i}(0.002-0.014)\end{array}$ & $\begin{array}{c}(1.41-1.77)- \\
\mathrm{i}(0.002-0.014)\end{array}$ & $\begin{array}{l}(1.41-1.77)- \\
\mathrm{i}(0.002-0.013)\end{array}$ & $\begin{array}{l}(1.42-1.78)- \\
\mathrm{i}(0.001-0.010)\end{array}$ & $\begin{array}{l}(1.42-1.79)- \\
\mathrm{i}(0.001-0.008)\end{array}$ \\
\hline $\begin{array}{c}\text { Mixed } \\
\text { aerosol } \\
(\mathrm{AE} \leq 0.75)\end{array}$ & $\begin{array}{c}(1.48-1.61)- \\
\mathrm{i}(0.004-0.010)\end{array}$ & $\begin{array}{c}(1.48-1.61)- \\
\mathrm{I}(0.002-0.007)\end{array}$ & $\begin{array}{c}(1.48-1.61)- \\
\mathrm{i}(0.002-0.007)\end{array}$ & $\begin{array}{c}(1.48-1.61)- \\
\mathrm{i}(0.002-0.006)\end{array}$ & $\begin{array}{c}(1.48-1.61)- \\
\mathrm{i}(0.002-0.006)\end{array}$ & $\begin{array}{c}(1.48-1.61)- \\
\mathrm{i}(0.002-0.006)\end{array}$ & $\begin{array}{c}(1.48-1.61)- \\
\mathrm{i}(0.002-0.005)\end{array}$ & $\begin{array}{c}(1.48-1.61)- \\
i(0.002-0.005)\end{array}$ & $\begin{array}{c}(1.48-1.61)- \\
i(0.002-0.004)\end{array}$ \\
\hline $\begin{array}{c}\text { Mixed } \\
\text { aerosol } \\
(A E>0.75)\end{array}$ & $\begin{array}{c}(1.43-1.73)- \\
\mathrm{i}(0.002-0.019)\end{array}$ & $\begin{array}{c}(1.43-1.73)- \\
\mathrm{i}(0.002-0.015)\end{array}$ & $\begin{array}{l}(1.43-1.73)- \\
\mathrm{i}(0.002-0.014)\end{array}$ & $\begin{array}{c}(1.43-1.73)- \\
\mathrm{i}(0.002-0.013)\end{array}$ & $\begin{array}{c}(1.43-1.73)- \\
\mathrm{i}(0.002-0.012)\end{array}$ & $\begin{array}{c}(1.43-1.73)- \\
\mathrm{i}(0.002-0.012)\end{array}$ & $\begin{array}{c}(1.43-1.73)- \\
\mathrm{i}(0.002-0.011)\end{array}$ & $\begin{array}{c}(1.43-1.73)- \\
i(0.001-0.009)\end{array}$ & $\begin{array}{c}(1.43-1.74)- \\
\mathrm{i}(0.001-0.007)\end{array}$ \\
\hline
\end{tabular}

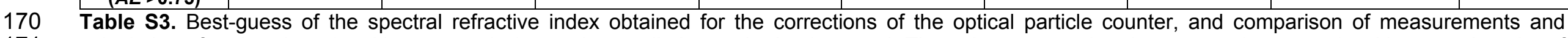

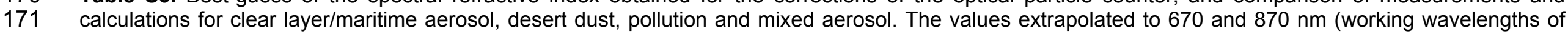
172 POLDER-3) are also shown. 
174 The results of the comparison at $550\left(\sigma_{\text {scat }}\right)$ and $532 \mathrm{~nm}\left(\sigma_{\text {ext }}\right)$ are illustrated in Figure S6. The 175 uncertainties associated with the evaluation of the size distribution, the measured scattering 176 and extinction, and finally the aerosol optical depth retrieved are estimated as the quadratic 177 sum of the instrumental uncertainties as well as with the variability due to the reduction of the 178 native time-resolution to a common time step of 30 seconds, a standard deviation generically 179 indicated here as $\Delta_{30 \mathrm{sec}}$. The instrumental uncertainties for the nephelometer and the CAPS180 PMex are evaluated as $\pm 10 \%$ for submicron aerosols (Anderson et al., 1996), and $\pm 3.2 \%$ 181 (Massoli et al., 2010), respectively. The error on the number of particles $n_{i}(i=$ generic bin) 182 follows the Poisson's law as $\Delta$ Poisson $=\sqrt{n_{i}}$. The comparison between measured and calculated $183 \sigma_{\text {scat }}$ at 450 and $700 \mathrm{~nm}$ are not shown as they are analogous to those at $550 \mathrm{~nm}$. 
CLEAR
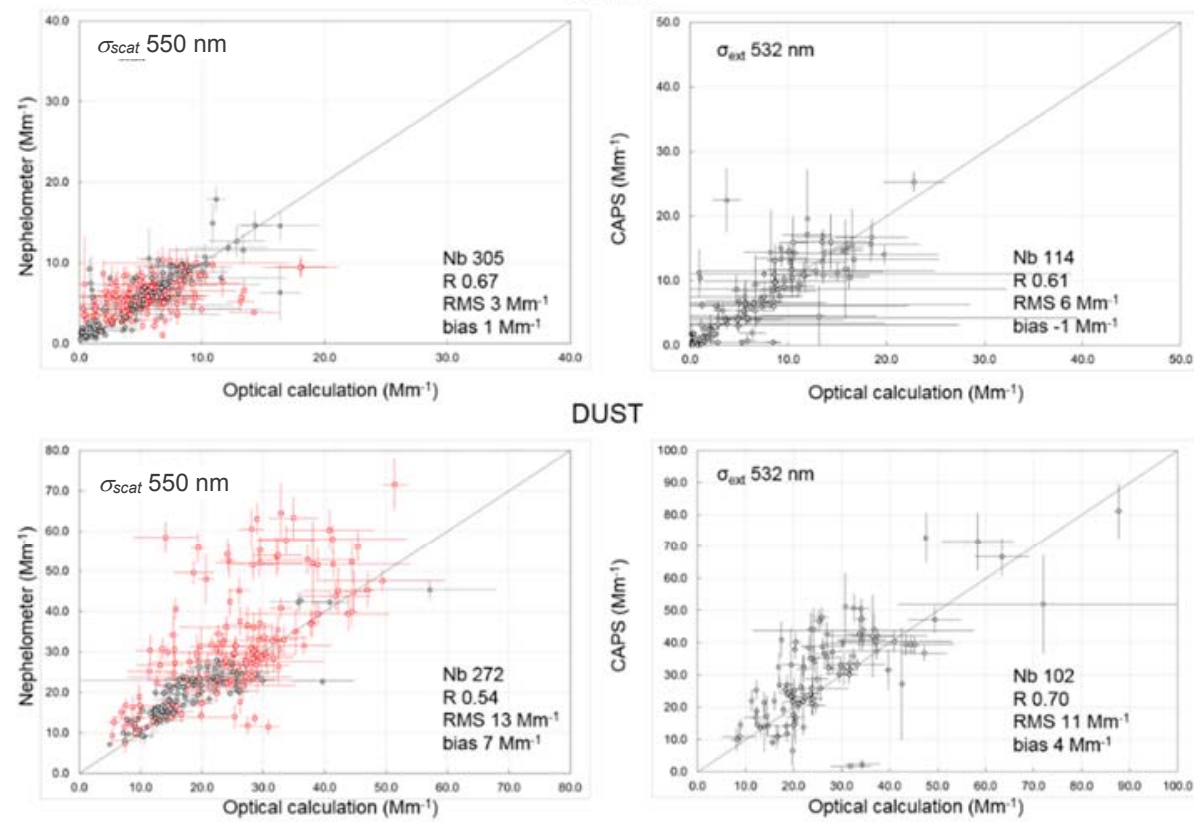

POLLUTION
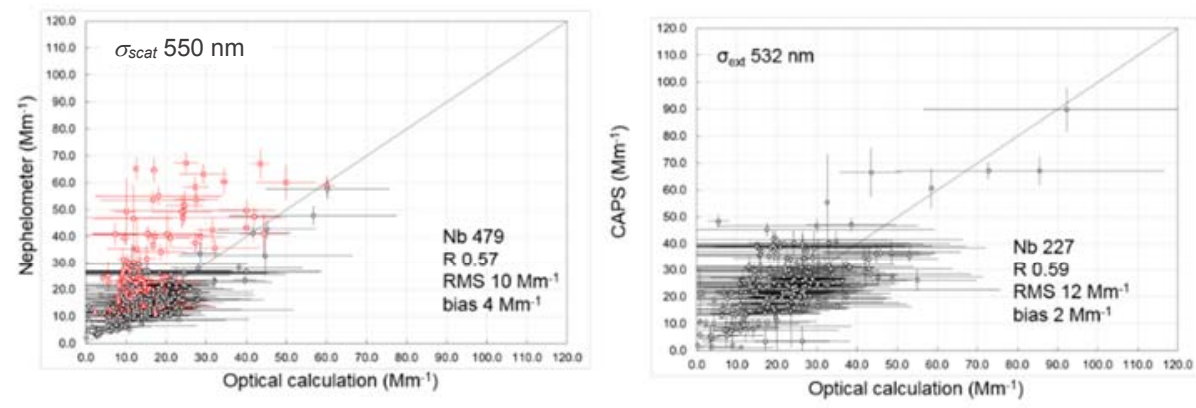

MIXED
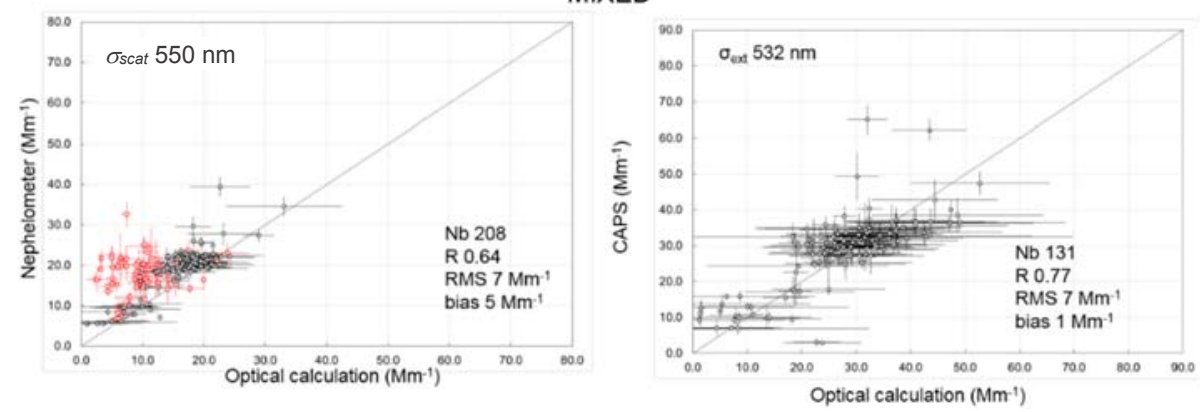

Figure S6. Comparison of optical calculation and measurements of $\sigma_{\text {scat }}$ at $550 \mathrm{~nm}$ and $\sigma_{\text {ext }}$ at $532 \mathrm{~nm}$ for all aerosol layers of all vertical profiles during TRAQA (red) and ADRIMED (black) campaigns. The comparison for $\sigma_{\text {ext }}$ is shown only for ADRIMED since there were no CAPS-PMex measurements during TRAQA. See the text for error bars calculation.

The comparison is satisfactory for all aerosol types, and in particular concerning $\sigma_{\text {ext. }}$ The systematic underestimation of the larger values of $\sigma_{\text {scat }}$ during TRAQA is due to the faulty operation of the Grimm OPC above $350 \mathrm{~m}$ from sea level. These data points were removed from the dataset for POLDER-3 $A O D$ and $A O D_{c}$ evaluation while kept for the evaluation of 
$195 A O D_{F}$ which is not affected by errors in sizing the largest particles. The uncertainties for the 196 optical computation of $\sigma_{\text {scat }}$ are higher for pollution layers than for other types of aerosols. This 197 is due to the wide range of possible values of the refractive index. 